\title{
Las galerías filtrantes del Alto Lerma: usos y manejos sociales
}

\section{The filtering galleries in the Upper Lerma River: uses and social managements}

\author{
Roberto Montes-HernándeZ* \\ Alejandro Tonatiuh Romero-Contreras* \\ Carlos Solís-Morelos* \\ María Gladys Rivera-Herrejón* \\ Sergio Zamorano-Camiro**
}

\begin{abstract}
The location and study of the social management of water of the filtering galleries in the State of Mexico has not been performed because the existence of this hydraulic system is ignored. In the present article the geo-referencing and description of the use and social management of water of the filtering galleries in the Upper Lerma are presented for the first time. On the basis of fieldwork, review of files and ethnography, we verify and describe the existence of said system in the region. The development of this work is part of a broader research called "Characterization of the use and social management of water of the filtering galleries in the State of Mexico" under the supervision of Tonatiuh Romero.
\end{abstract}

Keywords: localization, location, filtering gallery, technology, use and social management of water.

\section{Resumen}

La ubicación y estudio del manejo social del agua de las galerías filtrantes en el Estado de México no se ha realizado porque se ignora la existencia de este sistema hidráulico. En el presente artículo se informa por primera vez la georreferenciación y descripción del uso y manejo social del agua de las galerías filtrantes del Alto Lerma. Con base en trabajo de campo, revisión de archivos y etnografía, se verifica y describe la existencia de dicho sistema en esta región. El desarrollo de este trabajo es parte de una investigación más amplia, denominada "Caracterización del uso y manejo social del agua de las galerías filtrantes en el Estado de México", bajo la supervisión de Tonatiuh Romero.

Palabras clave: localización, ubicación, galería filtrante, tecnología, uso y manejo social del agua.

* Universidad Autónoma del Estado de México, México. Correos-e: betomh_13@yahoo.com. mx, lautona@aol.com,csolism@uaemex,griverah@uaemex.mx.

** Secretaría de Desarrollo Agropecuario, México. Correo-e: szc123@prodigy.net.mx. 


\section{Introducción}

Hasta ahora se había ignorado la existencia de las galerías filtrantes en el Estado de México. Debido a su importancia para contribuir a la captación de agua y combatir la escasez del vital líquido, se llevó a cabo su ubicación (georreferenciación), identificación, caracterización social y tecnológica en el Alto Lerma. Diferentes autores coinciden en que el qanat, o galería filtrante, fue un sistema que se originó, usó, manejó y difundió en ambientes de tipo desértico, como método fundamental en el abastecimiento sustentable de agua desde tiempos remotos.

Los investigadores Alfonso y Gilberto Fabila (vol. I, 1951: 128), en su monumental trabajo intitulado: México, ensayo socioeconómico del Estado, señalan puntualmente la inexistencia de túneles o galerías filtrantes en el Estado de México. Con ello desalentaron la búsqueda del sistema en la entidad por otros autores. Por otra parte, en el Atlas ecológico de la Cuenca Hidrográfica del Río Lerma (Peña, 2000: 149), encargado de ubicar y señalar las formas de abastecimiento de agua, tampoco se reporta la existencia de galerías filtrantes. Por lo anterior, en el presente escrito se brinda por primera vez, a través de trabado de archivo, etnográfico y de campo, la localización, ubicación y descripción del uso y manejo social del agua de las galerías filtrantes del Alto Lerma.

La región seleccionada para el estudio social del agua de las galerías filtrantes o qanats, es la cuenca Alta del Río Lerma, la cual está constituida de un paisaje donde las variadas actividades humanas interactúan con los diferentes recursos naturales (GEA, 2000: 13). Para lograr la localización y ubicación de galerías filtrantes en el Alto Lerma se tomaron en consideración los posibles nombres que recibe el sistema; se revisaron las cartas topográficas del INEGI 1: 50,000 cobertura del Alto Lerma (enfatizando en las características hidráulicas); se hicieron consultas bibliográficas y de documentación en archivos antiguos y modernos.

En el Archivo Histórico del Estado de México se consultó un total de 38 expedientes útiles con 1,826 fojas con información respecto al tema. En el Archivo Histórico del Agua se investigaron 13 expedientes con 847 fojas útiles. Finalmente, por medio de trabajo de campo, etnografía y tradición oral se ubicaron los sistemas y se definió cuáles sistemas eran en realidad galerías filtrantes. Con los datos obtenidos en campo de la georreferenciación de las galerías filtrantes, se realizó su representación cartográfica en el Alto Lerma.

Respecto a la Cuenca Alta se localizaron 11 municipios con reportes de galería filtrante, cuevas de agua, mina, túnel, socavón o veneros de agua, que son los nombres locales del mismo sistema, pero no en todas se confirmó. Con base en lo anterior se georreferenciaron y confirmaron en 
campo siete sistemas de galerías filtrantes pertenecientes a los municipios de: Toluca (1 que no funciona), Zinacantepec (1), Almoloya de Juárez (1 destruido), Ocoyoacac (1), San Felipe del Progreso (2), Acambay (1). De éstos se describen seis, de los cuales cinco se usan y manejan en la actualidad por organizaciones sociales locales del agua, pertenecientes a cuatro municipios del Alto Lerma; asimismo se documenta un sistema destruido, debido al desconocimiento e ignorancia de los usuarios de cómo funciona y se mantiene.

\section{Las galerías filtrantes en el mundo}

Las galerías filtrantes se denominan y conocen con distintos nombres en diversas partes del mundo y de México (por ejemplo, se les llama qanats o foggaras, entre otros). Raymond Furon (1967) señala que hay dudas en cuanto al origen y difusión de estas construcciones en el Viejo Mundo. Se sabe que eran conocidas por los asirio-babilonios y los persas de la antigüedad protohistórica, que las utilizaron los romanos en Siria, luego los turcos en Asia Menor. Existen en el Turquestán, en el Turfán y en el Sinkiang en China. La presencia de las primeras ciudades en estos lugares estuvo vinculada a la construcción de este sistema; y de la ciudad bíblica de Qana posiblemente se deriva el nombre de los qanat, que asegura la provisión de agua. Con estos sistemas se abastecieron diversas ciudades como Jerusalén y Jericó, entre otras (Furon, 1967; Prieto, 2001).

El arquitecto Prieto (2001), en su Atlas del agua, pone énfasis en los conocimientos tradicionales para combatir la desertificación, y narra los distintos sistemas y técnicas de captación de agua en lugares inaccesibles al agua superficial, destacando el caso del sistema de foggaras en las zonas áridas.

La tecnología del qanat se difundió primero a través del Viejo Mundo. $\mathrm{Al}$ oeste, los qanat se construyeron en Mesopotamia a orillas del Mediterráneo, así como en partes de Egipto; al este de la antigua Persia, en parte del Sahara. Los qanat también están presentes en Afganistán, en los arcaicos establecimientos de seda de los oasis de la ruta del Asia Central, así como del Turkistán chino (El Turpan). Durante la era romana-bizantina (64 a.C.), se construyeron muchos en Siria y Jordania. De ahí la tecnología se difunde al norte y oeste en Europa.

La expansión del islam inició otra difusión importante de la tecnología del qanat. Las invasiones árabes tempranas lo llevaron al oeste a través de África del Norte y en Chipre, Sicilia, España y las Islas Canarias. En Espańa, los árabes construyeron un sistema de qanat en Crevillente, muy probablemente para el uso agrícola, y otros en Madrid y Córdoba para el abastecimiento urbano de agua (Prieto, 2001). 
Posterior a la conquista española, los qanats se difundieron en América Latina: en el norte de Argentina; en Perú, en su parte del desierto de Atacama y en Nazca; en Bolivia, y en el Cuadratín en Chile (Wilken, 1990). El investigador Richard K. Cleek (1973) se inclina por la posibilidad de que las galerías filtrantes las difundieran en México las órdenes religiosas, especialmente por los franciscanos y la Compañía de Jesús. Otros estudiosos comparten esta opinión, como Luis Blázquez (1957) y Enno Seele (1969), quienes señalan como fecha de aparición de los qanats la época inmediatamente posterior a la conquista, así ofrecen datos que apoyan de manera tentativa esta tesis (Wilken, 1990: 277, 281).

\title{
2. Las galerías filtrantes foggaras o qanat: un intento de definición
}

Investigadores como Cleek (1973), Monterrosa (1976), Henao (1980), Wilken (1990), Prieto (2001), Palerm (2001) y Martínez et al. (2005) coinciden en gran parte con la definición de galerías filtrantes que plantea el profesor Raymond Furon:

\begin{abstract}
Al lado de los acueductos aéreos que conducen hasta su punto de destino las aguas de manantiales lejanos, existen acueductos subterráneos que transportan las aguas desde el nivel freático. Hay a veces reservas de agua en los desmoronamientos de las pendientes, al menos cuando la naturaleza litológica da pie a ello. Se puede llegar hasta esta agua por medio de pozos, y se la conduce luego de su punto de origen por largas galerías subterráneas. [... ] Por lo que estos acueductos subterráneos se ven en la superficie del suelo bajo la forma de grandes toperas alineadas, estos pequeños montículos están formados por los escombros del pozo que se encuentra en el centro. Los pozos comunican entre sí por una galería lo bastante alta para que un hombre circule dentro de pie. El arte consiste en construir de este modo una galería de varios kilómetros de longitud con una pendiente suave y regular, llevando el agua desde el río arriba hasta una parte de río abajo. Las pendientes más corrientes son del 1 al 8\%" (Furon, 1967: 90-91; imagen I).
\end{abstract}

Las galerías filtrantes se conocen con distintos nombres en diferentes partes del mundo: kiraz, kériz, kariz, en Afganistán y en Persia; qanat en Persia; sabrig en Yemen; kriga en el sur de Túnez; foggara en el Sahara; khattara en el sur de Marruecos; falaz en Arabia; picos en Madrid; viaje o viaje de agua (una deformación del nombre latino via acquae) en el sureste de España. En España y Francia, en tiempos recientes, utilizan la terminología de galerías de drenaje, galerías de captación de agua por drenaje; madjirat en regiones andaluzas. En distintas partes del Viejo Mundo también se conocen con el nombre de fuqara, hattara, karez, rhettara, réthara, khettara, falaj, mambo, alcavor, minas de agua, galerie filtrante, infiltration gallery, chain well, chain of wells, pozos horizontales, pozos en cadena, galeria filtrón, underground aqueduct chain well. 


\section{Imagen I \\ Representación general de la construcción de la galería filtrante en el Viejo Mundo}

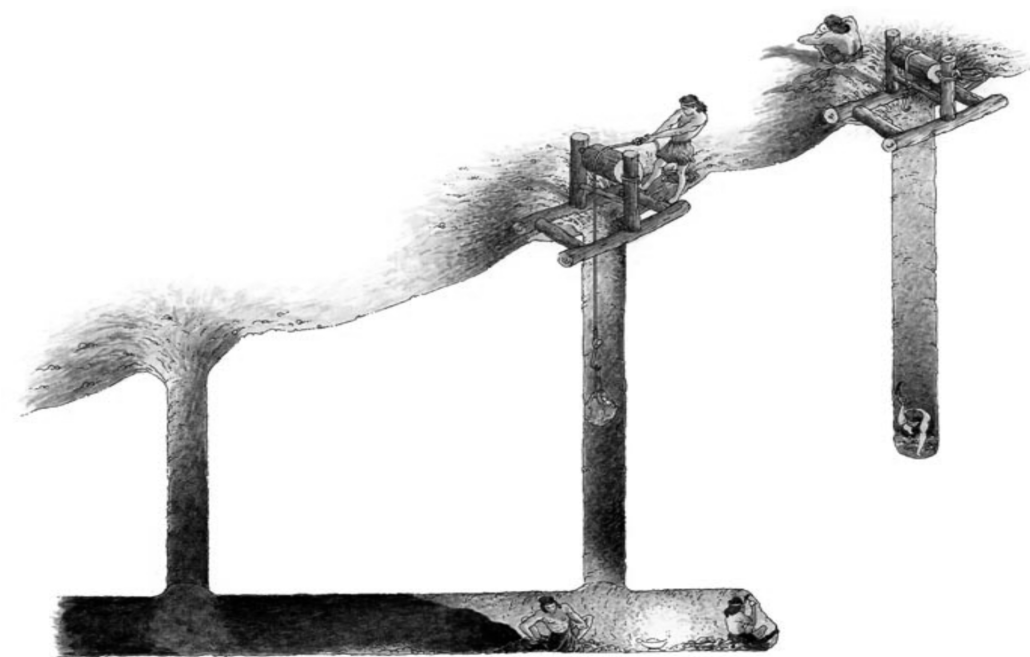

Fuente: "Murcia y el agua. Historia de una pasión", <http://servicios.laverdad.es/murcia_agua/infografias.htm>, 13 de marzo, 2007.

En México y América Latina reciben el nombre de galería filtrante; aunque en Perú también se les llama pukios, entre otros nombres locales. En México, específicamente en Tehuacán, Puebla, se les conoce como apantles con tragaluces, pozería, galería filtrante (o nada más galería); fuques en el Distrito de Riego Valsequillo o Tecamachalco, Puebla; en Parras, Coahuila: galería con lumbreras o venas de Dios. En el Estado de México se les denomina galera, cuevas de agua, túnel, veneros de agua, galería filtrante (o en algunos casos las identifica con el nombre del paraje en el que se encuentra el sistema) (Furon, 1967: 90; Prieto, 2001: 258; Palerm et al., 2001; Martínez et al., 2005; Romero, 1998; Montes, 2005-2008).

La imagen II representa de manera fiel tres modos de aprovechar el agua para riego en tiempos antiguos en la meseta iraní, donde: 1) en la parte superior los campos son regados principalmente por la lluvia, por estar en pendiente, lejos del vado o curso de agua cercano; 2) en el centro hay campos que están regados por acequias precedentes del qanat, y 3) en la parte inferior una serie de agujeros indican la presencia de un qanat, acueducto bajo tierra que recoge aguas freáticas. 


\section{Imagen II \\ Representación general del uso de las galerías filtrantes en el Viejo Mundo}

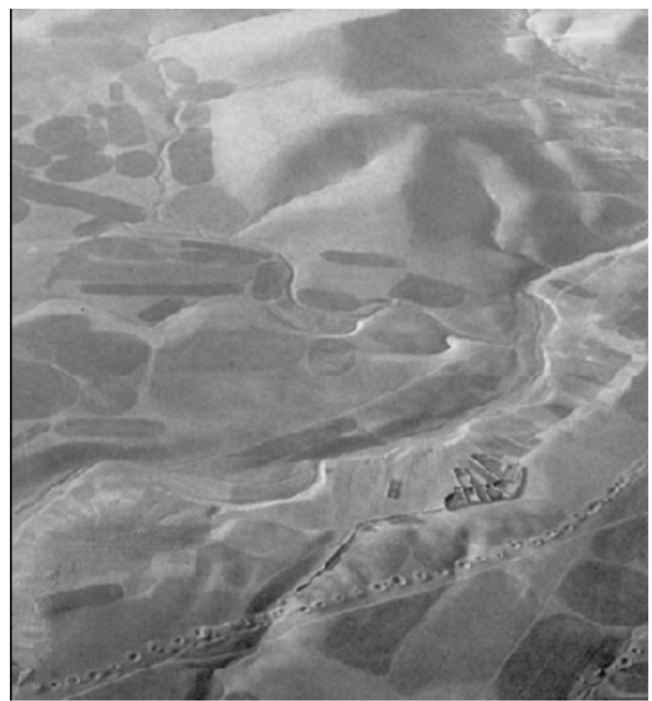

Fuente: Norton, 1982, modificada por Montes, 2006.

\section{El Alto Lerma mexiquense: ambiente y límites}

De acuerdo con el Atlas etnográfico de la Cuenca Alta del Río Lerma (Sugiura et. al., 1993) y el Atlas ecológico de la Cuenca Hidrográfica del Río Lerma: industrial (Peña, 2000), dicha cuenca se localiza en la porción oeste del Estado de México que rodea al Distrito Federal, entre los $19^{\circ}$ $15^{\prime}$ y $20^{\circ} 05^{\prime}$ de latitud norte y los $99^{\circ} 25^{\prime}$ y $100^{\circ} 15^{\prime}$ de longitud oeste. Presenta una forma alargada irregular con orientación noroeste-sureste, con una longitud de 133 kilómetros, con una variedad de topoformas características de su génesis y procesos que le dieron su morfología actual.

Dentro de los límites estatales se encuentra regionalizada en cursos alto, medio y bajo. El primero de ellos se considera desde su más elevada cota, en el Nevado de Toluca, hasta la entrada a la presa J. A. Alzate en los municipios de Toluca y Temoaya. La segunda sección se considera desde el embalse Alzate hasta los límites del los municipios de San Felipe del Progreso, Jocotitlán y Atlacomulco. El tercero y último tramo comprende los municipios de El Oro, Temascalcingo y Acambay (mapa I). La dinámica de las aguas subterráneas en la cuenca del Alto Lerma constituye un pilar en el desarrollo de la región. El abastecimiento de agua potable para todas y cada una de las poblaciones y establecimientos industriales de la cuenca es posible a través de la explotación del manto freático. 


\section{Mapa I}

\section{Localización de las galerías filtrantes de la Cuenca Alta del Río Lerma}

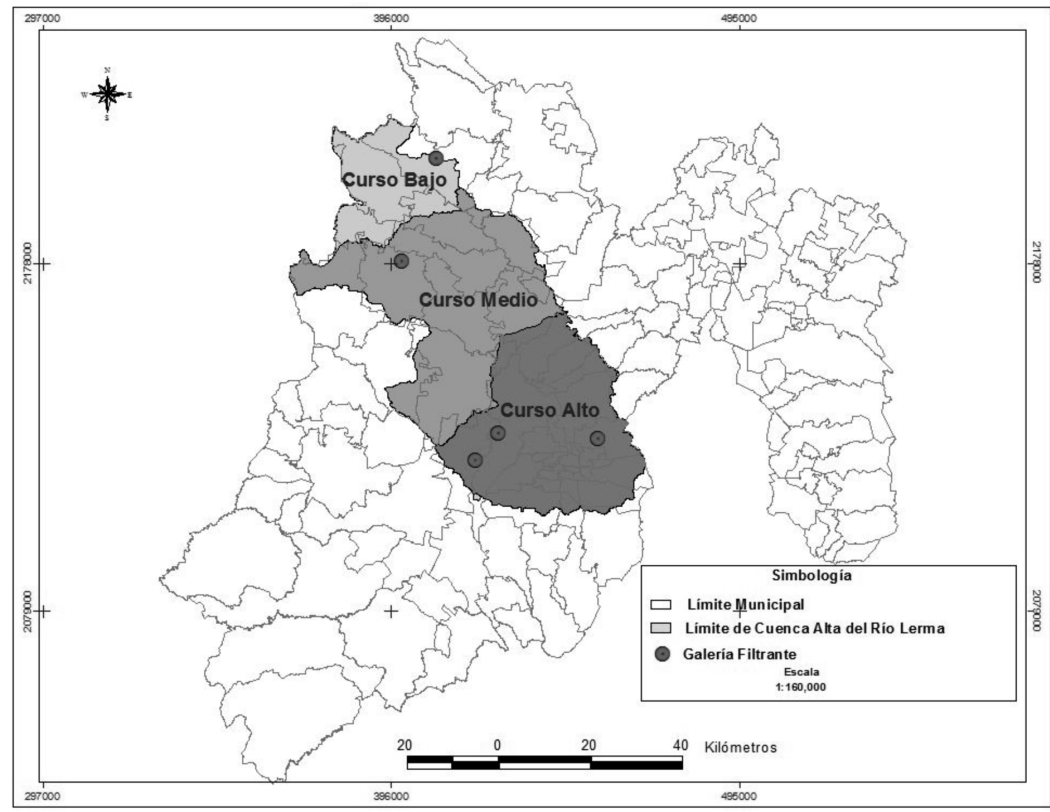

Fuentes: Montes (2005-2008); trabajo de campo.

El flujo de agua subterráneo tiene como principal zona de recarga el Nevado de Toluca y circula hacia el valle en dirección este y norte, recorre una primera sección en intensa explotación correspondiente al curso alto en dirección predominante sur-norte, posteriormente su orientación se modifica al noroeste por influencia de los embalses Antonio Alzate e Ignacio Ramírez, donde entra a una segunda sección de menor explotación, es decir, a los cursos medio y bajo (GEM, 2000: 146).

De manera general, la situación geográfica de la Cuenca Alta del Río Lerma hace posible la manifestación de diversas condiciones atmosféricas a lo largo del año, la nubosidad y las lluvias son más abundantes en esta región, en el transcurso de todas las estaciones del año en relación con el curso bajo. La geomorfología de la Cuenca Alta se caracteriza porque está formada por materiales volcánicos de diferentes épocas, donde predominan los suelos del tipo andosol (GEM, 2000).

Según el Atlas etnográfico de la Cuenca Alta del Río Lerma (1997), en su recorrido a través del Valle de Toluca se agrupan 32 municipios, habitados actualmente por cuatro grupos étnicos que comparten una misma historia: otomíes, mazahuas y matlatzincas, a la que después se agregan con mayor presencia los nahuas procedentes de la expansión del imperio azteca. 


\section{Las galerías filtrantes en el curso alto de la Cuenca del Lerma}

El orden en que se describen las galerías filtrantes en el presente escrito es de acuerdo con los cursos alto, medio y bajo. En la cartografía del Atlas ecológico de la Cuenca Hidrográfica del Río Lerma (1993), se señala que el curso alto del Río Lerma comprende 22 municipios, de los cuales sólo en Zinacantepec, Almoloya de Juárez y Ocoyoacac se encontraron galerías filtrantes, mismas que se georreferenciaron y se describió el uso y manejo social del agua.

\subsection{Zinacantepec, galería Túnel de Romero perteneciente a San Juan de las Huertas, antes a la antigua hacienda de la Huerta}

Producto de la consulta en el Archivo Histórico del Estado de México, ${ }^{1}$ se localizó una galería filtrante en el Parque Nacional Nevado de Toluca, al sur del curso alto del Lerma, construida en el siglo XIX por los dueños de la antigua hacienda de San Juan de las Huertas. El agua de dicha galería fue solicitada después de la Revolución para regadío de las parcelas de los campesinos del ejido de Ojo de Agua, municipio de Zinacantepec, por lo que el comisionado, ingeniero Benito Martínez Barragán, en su inspección reglamentaria de las aguas, mencionó que

La fuente aprovechable o que desean aprovechar para riego de una parte de su ejido, son las aguas producidas por el Túnel de Romero, que es una excavación horizontal entrante en el cerro, cuya longitud y sección no fue posible medir [...]. En este túnel o galería afloran aguas de régimen permanente que corren de sur a norte en general por la barranca de Túnel de Romero, que aproximadamente a un kilómetro de longitud de esta barranca se juntan con las aguas que corren por la barranca del Romero, también conocida por la Barranca de Los Cipreses, río Chiquito o río de La Huerta. Este último habiéndose declarado de propiedad nacional el 6 de julio de 1929, y del cual la Secretaría de Agricultura y Fomento ha reglamentado y distribuido todas sus aguas mansas entre diversos usuarios que se encuentran aguas abajo. Aunque en la declaratoria anterior no se mencionan las aguas del Túnel de Romero. ${ }^{2}$

En el informe en relación con el Mandamiento Rotatorio de Aguas, el gobernador Wenceslao Labra menciona que "La Junta de Aguas del Río Tejalpa y sus afluentes recibió notificación para los usuarios de las aguas del paraje conocido con el nombre de 'Túnel de Romero' con fecha 16 de febrero de $1938 .^{3}$

\footnotetext{
${ }^{1}$ AHEM/CAM/1938-1946/Vol. 121/Exp. 2-1424/F. 21.

2 AHEM/CAM/1938-1946/Vol. 121/ Exp. 2-1424/F. 21.

${ }^{3}$ AHEM/CAM/1938-1946/Vol. 121/Exp. 2-1424/F. 49.
} 
Finalmente, con respecto a la vista práctica a las fuentes de aprovechamiento (al Túnel de Romero), el ingeniero Darío Meixueiro mencionó lo siguiente:

En mi concepto, de ejecutarse este municipio con el total del volumen de aguas del Túnel de Romero, desviándolas para regar los terrenos ejidales del poblado Ojo de Agua, los actuales usuarios del Río Tejalpa y sus afluentes resentirían la falta de esta corriente por los riegos a que están acostumbrados hacer [...].

Existe otra circunstancia por la cual no podría ejecutarse el Mandamiento Rotatorio de Aguas del C. Gobernador y que se debe tener de una manera especial en cuenta: los vecinos del poblado de San Juan de las Huertas han conseguido de la Secretaría de la Asistencia Pública que ingenieros de esta dependencia hayan verificado estudios y trabajos de campo para proyectar la introducción del agua de este manantial, Túnel de Romero, para los servicios públicos y domésticos de este mismo poblado y solamente falta instalar la tubería de conducción de aguas, por cuya circunstancia se hace necesario solicitar los informes correspondientes a dicha Secretaría, con el fin de no crearse un conflicto entre los vecinos de Ojo de Agua y San Juan de la Huertas, al consumarse la ejecución del Mandamiento Rotatorio de Aguas al primero de los poblados mencionados. ${ }^{4}$

La aprobación de la dotación del agua de la galería filtrante al pueblo de Ojo de Agua, se publicó el miércoles 18 de octubre de 1944 en la Gaceta de Gobierno del Estado de México (p. 5). ${ }^{5}$

\subsubsection{Ubicación de la galería filtrante}

En entrevista llevada a cabo el 22 de enero de 2008, el señor Primitivo Monroy, presidente del comisariado ejidal del poblado de Ojo de Agua, perteneciente a San Juan de Las Huertas, Zinacantepec, comentó que "no conoce los términos verdaderos del por qué no se les dotó de agua de esa galería filtrante. Esa fuente de agua no nos pertenece y la petición no procedió. Esa agua la levantaron ellos, nosotros no tenemos ni beneficio de agua para riego, eso pertenece allá, no tenemos manantial para riego".

Posteriormente, en la localidad de San Juan de las Huertas, el fontanero mostró el lugar donde se localiza el Túnel de Romero, el cual se ubica al sur del poblado, en las coordenadas X: 0419892 y: 2123109, a una altura de 3,301 metros sobre el nivel medio del mar (mapa I).

Por su parte, la licenciada Reina Cevallos Garduño, tesorera del Comité de Agua Potable de San Juan de las Huertas, en entrevista el 22 de enero de 2008 mencionó que "El Túnel de Romero lo tenemos nosotros, es de donde se capta y traemos el agua. Nuestro sistema de agua potable

\footnotetext{
${ }^{4}$ AHEM/CAM/1938-1946/Vol. 121/Exp. 2-1424/ Fs. 50-51.

${ }^{5}$ AHEM/CAM/1938-1946/Vol. 121/Exp. 2-1424/F. 44.
} 
data de 1947; pero es más antigua su construcción, un año después de la solicitud que hicieron los del poblado Ojo de Agua.

\title{
4.1.2. Uso y manejo actual del agua: infraestructura y organización social
}

En cuanto a tecnología e infraestructura, el señor fontanero Faustino, en entrevista el 1 de enero de 2008 menciona:

\begin{abstract}
Traemos una tubería de 4 pulgadas proveniente del Túnel de Romero, se puede observar la tubería antigua que es de hierro, misma que apenas da abasto para llevar el agua a los depósitos. Tenemos otros manantiales denominados La Pedrera y captación La Guacamaya. Los tres llegan a los depósitos ubicados en el paraje que se le denomina Recibitas, por allá arriba, ya que en el sistema en su totalidad la distribución del agua es por gravedad, excepto la del pozo.
\end{abstract}

La organización social encargada del uso y manejo del agua de San Juan de las Huertas, se denomina Comité de Agua Potable y está integrado por un presidente, León Nente Iglesias; una tesorera, Reina Cevallos Garduño; el comité de vigilancia, Demetrio Chávez López (abandonó el cargo a las dos semanas); dos fontaneros titulares y uno de apoyo. Todos ellos fueron elegidos por medio del sistema de usos y costumbres que tiene el pueblo, por votación cada tres años.

Antes de la reforma agraria, el mantenimiento de El Túnel estaba a cargo del administrador de la hacienda de La Huerta, y se hacía mediante la limpieza de los acasillados. En la actualidad, la construcción está en perfectas condiciones, producto de su correcto uso y mantenimiento; a pesar de que El Túnel no ha recibido reparación alguna en los últimos 15 años, sólo la parte de la bocatoma, recibe limpieza debido a la arena que se llega a juntar por el arrastre que causa el agua de la misma, y son los fontaneros quienes se encargan de darle mantenimiento cada cinco o más años.

En entrevista el 1 de febrero de 2008, Faustino Flores comentó que "La conducción del agua del Túnel llegaba allá donde estaba el internado, en la Hacienda. Por lo que se sabía de esta agua, la utilizaban para el riego de algunos terrenos, además, la acumulaban en un bordo que a la fecha ya no existe, ubicado en lo que fue la hacienda de La Huerta.

En entrevista el 22 de enero de 2008, Reina Ceballos nos explico cómo hacen el manejo social del agua del qanat:

La distribución del agua se realiza por tandeos, un día sí y dos días no, debido a que no tenemos una cultura del agua y no podemos dejar que se desperdicie, además de que nuestra red o línea de agua principal es tan vieja que no podemos dejarla que corra libre porque la presión afectaría la tubería y entonces se presentarían muchas fugas de agua. Nuestra red estaba calculada para una vida de 15 
años pero ya lleva 60 en servicio. No se han realizado cambios en la red, sólo se da mantenimiento donde se requiera.

Y precisamente yo traté que se aplicaran algunos recursos del gobierno para mejorar el sistema de agua potable pero no pude, debido a que no tenemos registrados los manantiales ante las instancias respectivas; sí había manera, pero no había apoyo de nuestro presidente municipal.

El presidente del Comité de Agua tiene la facultad de conceder nuevas tomas a los vecinos. El tesorero se encarga de cobrar 20 pesos mensuales por cada toma de agua. El secretario lleva la relación de los usuarios y constata que vayan al corriente con sus pagos.

Los dos fontaneros se encargan de revisar el sistema, distribuir el agua, colocar nuevas tomas y el mantenimiento de los canales. Ellos son quienes tienen mayor conocimiento del sistema, dónde se ubican los manantiales, el tendido de toda la red de agua, válvulas y horarios de la distribución del líquido; también se encargan del mantenimiento y tienen un salario.

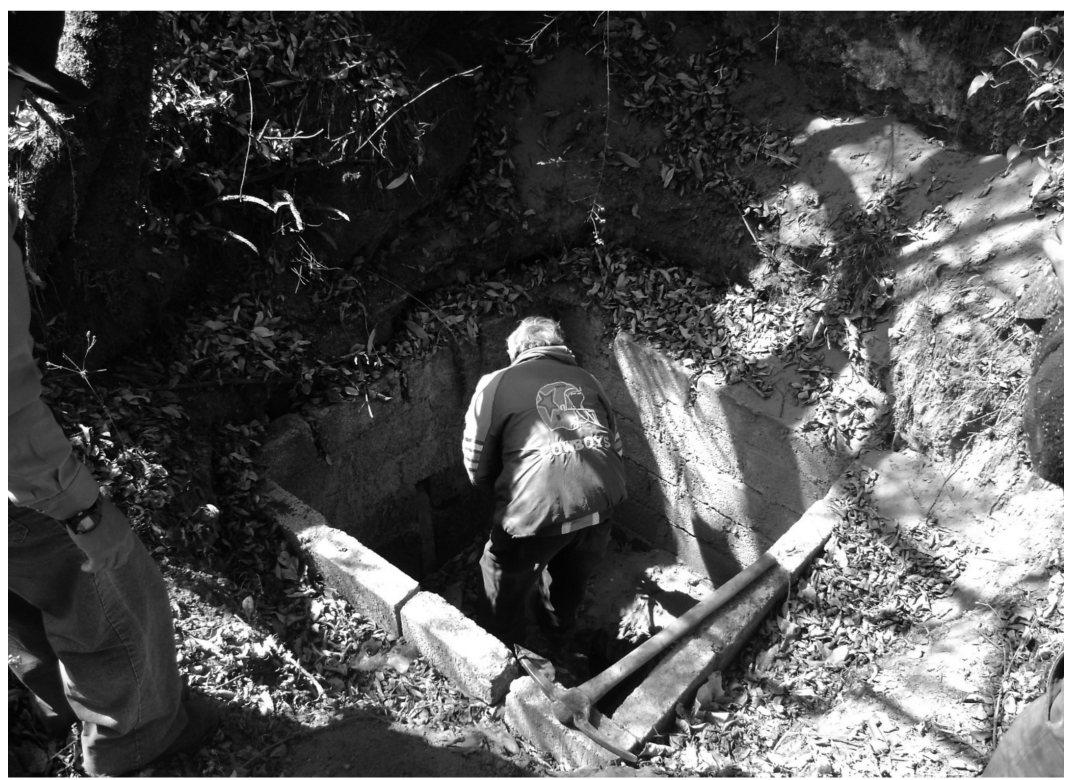

El fontanero quita la tapa del registro de la entrada a la galería filtrante del Túnel de Romero. Fuente: Roberto Montes (2008). 


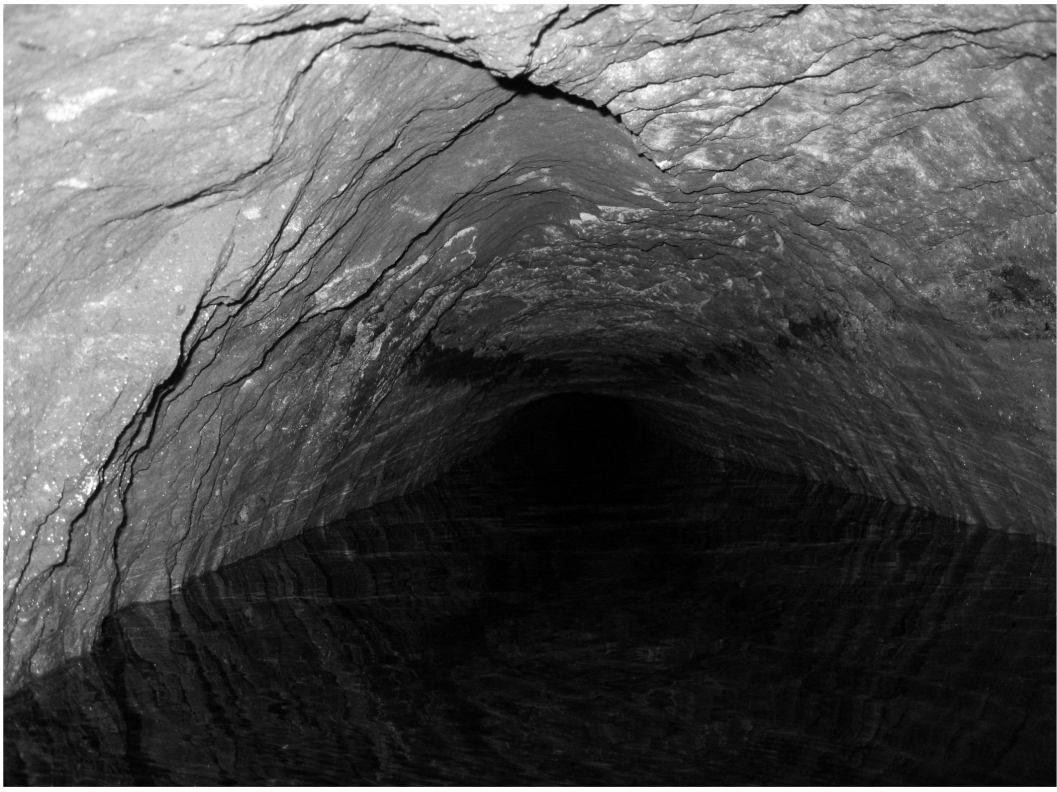

Vista interior de la galería.

Fuente: Roberto Montes (2008).

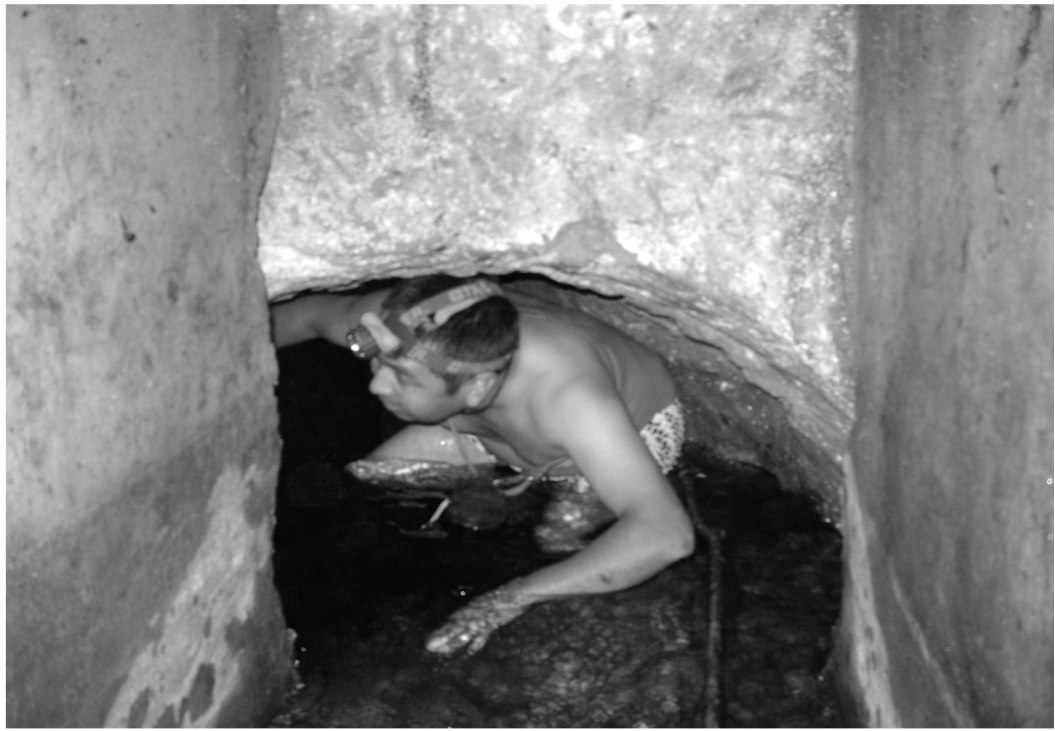

Exploración del interior del sistema.

Fuente: Roberto Montes (2008). 


\subsection{Almoloya de Juárez, galería ubicada en la carta topográfica INEGI 1: 50,000, perteneciente al Barrio de Coporo de Santa María del Monte}

Mediante comunicación personal, el investigador Tonatiuh Romero (2003) señaló que en una consulta realizada en la cartografía INEGI 1: 50,000 , de la región del centro de México, en la simbología correspondiente a los rasgos hidrológicos existe el registro de una galería filtrante. La clave de la carta es E14 A37 San Miguel Zinacantepec, al sur del poblado de Santa María del Monte, municipio de Almoloya de Juárez.

\subsubsection{Ubicación de la galería filtrante}

Para investigar dicha galería se hizo el recorrido el día 26 de enero de 2008, primero se visitó al personal de la delegación municipal de Santa María del Monte, donde los ejidatarios señalaron que la mencionada galería filtrante pertenecía al Barrio de Coporo de esta municipalidad, por lo que nos dirigimos hacia aquel lugar.

En entrevista, Manuel Colorado S., vecino del Barrio de Coporo, mencionó que el sistema se encuentra en el paraje denominado El Escobal, pero que fue destruido y alterada la filtración de agua a causa de los explosivos utilizados para aumentar su caudal. Por la vegetación y la escasa señal del sistema de posicionamiento global (GPS), sólo se ubicó el primer cárcamo contenedor del agua proveniente de la antigua galería, X: 0411982, Y: 2132330, a una altura de 3,301 metros sobre el nivel medio del mar.

\subsubsection{Uso y manejo actual del agua: infraestructura y organización social}

Con respecto a la tecnología e infraestructura de la antigua galería filtrante, el 26 de enero de 2008, Manuel Colorado S. mostró el sitio. Se observó que el sistema ya no existe, fue destruido al tratar de aumentar su caudal.

Lo que existe son los antiguos registros o cajas, ahora conectadas en serie para la captación del agua de distintos veneritos, infraestructura ya obsoleta, pero son las que han mantenido en función el sistema, es la antigua pero se sigue ocupando. En conjunto dan un gasto de 4 pulgadas de agua, mismas que alimentan la mayor parte del Barrio de Coporo. El diámetro del tubo es de 4 pulgadas, no ha sufrido ninguna modificación hasta la fecha, es de asbesto. Sólo se le ha colocado un poco de tubería de Pvc, se tiene un aproximado de 2 kilómetros de la fuente hasta el primer tanque de almacenamiento. 
Debido a las necesidades de abasto de agua para la creciente población del Barrio de Coporo de Santa María del Monte, fue destruida y alterada la filtración; por otra parte, también influyó la falta de conocimientos sobre el mantenimiento y ampliación del sistema. En la actualidad la población realiza excavaciones (zanjas) para tratar de alumbrar y captar más agua. Manuel Colorado presenta interés en rescatar el sistema, pero ahora a unos cuantos metros arriba del sistema original.

\subsection{Ocoyoacac, galería filtrante denominada El Túnel o El Aventurero, perteneciente a la antigua hacienda de Texcalpa, abora al Barrio de La Asunción Tepexoyuca}

En el mismo curso alto del Lerma, y mediante otro documento consultado en el Archivo Histórico del Estado de México, se detectó otra galería filtrante en Ocoyoacac. Con fecha de 10 de abril de 1942, el licenciado Luis Riba envío una carta al señor secretario de gobierno del Estado de México, solicitando el aprovechamiento del remanente de las aguas del ojo de agua El Túnel:

Soy dueño del rancho denominado "Texcalpa", situado en el municipio de Ocoyoacac, Distrito de Lerma, del Estado de México. El rancho antes mencionado se surtía de agua para las necesidades del casco y para el riego, de las aguas provenientes del ojo del agua conocido con el nombre de "El Túnel” o "El Aventurero", situado aproximadamente a 1,200 metros al oriente del casco. Dicho manantial fue propiedad del rancho, antes de que éste fuera afectado por los ejidos. ${ }^{6}$

En contestación por parte de la Secretaría de Fomento, en el oficio 377, con expediente 5/942, se establece el contrato de arrendamiento del remanente de las aguas provenientes de El Túnel, celebrándose lo siguiente:

\footnotetext{
Antecedentes

Tercera.- El Propietario desea aprovechar el remanente de dichas aguas para lo cual necesita hacer las obras necesarias para la introducción de la misma para su rancho Texcalpa, las que serán de su exclusiva cuenta y riesgo.

Cuarta.- El Ejido de Tepexoyuca no puede utilizar el remanente de dichas aguas sin hacer las obras necesarias para el uso de las mismas y firma el presente contrato en señal de conformidad con las cláusulas del mismo.

Cláusulas
} 
I.- El H. Ayuntamiento cede el uso del remanente de las aguas provenientes del manantial "El Túnel" al propietario del rancho de Texcalpa, durante 12 horas diarias de los 365 días del año.

II.- El remanente de las aguas a que se refiere la cláusula anterior no será inferior a 50 litros por minuto.

III.- El propietario se obliga a pagar al $\mathrm{H}$. Ayuntamiento la cantidad de $\$ 30.00$ (treinta pesos anuales) por el uso de las aguas referidas en las cláusulas anteriores. “...”.

IV.- El término de este contrato es de hasta el 31 de diciembre del año de 1943 mil novecientos cuarenta y tres, forzosos para ambas partes. v.- El propietario se obliga a hacer las obras necesarias para la introducción a su rancho y la captación de las aguas a que se refiere este contrato, por su cuenta. “...”?

\subsubsection{Ubicación de la galería filtrante}

Durante trabajo de campo el 29 de enero de 2008, en la localidad de La Asunción Tepexoyuca, Ocoyoacac, Julián Miranda Gumesindo, secretario del Comité de Agua, mencionó que "El Túnel está dentro de nuestro territorio y comprende tanto bienes comunales, ejido y parte de propiedad privada. El Encinal, La Perita y La Cuadrilla son también túneles pero no los estamos captando, lo ocupa poco la gente, el agua se va rodando, nadie los ocupa.

El túnel o qanat se ubica en las coordenadas X: 0454342, Y: 2129289, a una altura de 2,143 metros sobre el nivel medio del mar (mapa I).

\subsubsection{Uso y manejo actual del agua: infraestructura y organización social}

Con respecto a la tecnología y la infraestructura de este sistema, el 29 de enero de 2008, en entrevista, los integrantes del Comité de Agua Potable de La Asunción Tepexoyuca, señalaron lo siguiente:

El Túnel no pasa de más de seis o siete metros de longitud. Existen dos líneas de conducción: la antigua es de tubos de barro y la actual es de Pvc. La línea principal tiene como 1.5 a 2 kilómetros de longitud, aproximadamente. El gasto que da es de 4 pulgadas, el tubo que baja de allí es de 6 y 4 pulgadas, ahorita traerá como unas 3 o 4 pulgadas. En época de lluvias sí se llena la tubería, la escasez que se presenta es porque hacen falta árboles y yo pienso que por eso ha venido mermando. Nosotros no tenemos ningún convenio con los dueños de los terrenos por donde pasa la red de agua potable, y ellos están conscientes de que no deben ni pueden alterar la línea de agua potable. La capacidad de los depósitos es de $250 \mathrm{~m}^{3}$, el de El Encinal y el otro son más pequeños. 
La galería que se encuentra en La Perita es excavada y posteriormente le colocaron un tubo, el cual es recubierto con lajas de piedra. No es posible sacarle las medidas, ahorita aproximadamente da un gasto de una a dos pulgadas de agua, pero en época de lluvias da más de seis pulgadas. En cada uno de los tanques por donde pasa la línea principal de agua que viene del túnel hay un desfogue, por si hay que hacer mantenimiento.

El mantenimiento que se le da a este sistema es comunitario, se convoca e invita a faenas cuando se requiere, primordialmente cuando es afectada la línea de conducción principal o los desarenadores, y sólo cuando hay bastantes raíces que obstruyen la conducción del agua se adentran al túnel, lo cual se realiza anualmente. Este sistema se ve afectado por el crecimiento de las raíces de las plantas, sobre todo de árboles, lo cual le da un aspecto de abandono a la vista de los encargados y es el origen de los distintos comentarios y mitos creados en torno a El Aventurero, que a su vez sirven para resguardar y proteger la galería filtrante de incursiones.

La organización social que maneja actualmente el sistema de agua potable de Tepexoxuca es el Comité de Agua Potable de La Asunción Tepexoyuca; integrado por un presidente, Raymundo; un secretario, Julián Miranda Gumesindo; un tesorero, Humberto Corona Morales; un vigilante, Tomas Rodríguez, y un repartidor y vigilante de agua, Ascensión Flores Reyes, quien de 1993 a la fecha ha estado trabajando para el Comité (15 años laborando).

En entrevista en enero de 2008, el señor Flores Reyes comentó que en "la actualidad existe también un pozo profundo para complementar el abasto de agua potable al barrio y entre menos sea usado es mejor, porque no se gasta en insumos ni en mantenimiento del mismo, cuando se descompone hay que mandar traer a los ingenieros para que lo reparen y sale caro".

El reparto del agua es por manzanas, a su vez por calles y finalmente por tandas, mismas que se hacen por día. Dichas tandas son controladas por medio de válvulas; existen aproximadamente 40 registros en todo Tepexoyuca y cada uno de ellos tiene de dos a tres válvulas que controla el operador.

La galería filtrante es la principal fuente de abastecimiento de agua potable del Barrio de La Asunción Tepexoyuca, Ocoyoacac. Según informes del Comité de Agua Potable: "Somos como 25,000 habitantes, la mitad de la cabecera municipal, de los cuales supuestamente deben estar registrados unos 5,000 usuarios, pero como hay muchas irregularidades apenas se alcanzan a contabilizar de 1,500 a 2,000 tomas, pero sólo tenemos registradas aproximadamente 500 . Nosotros consideramos un usua- 


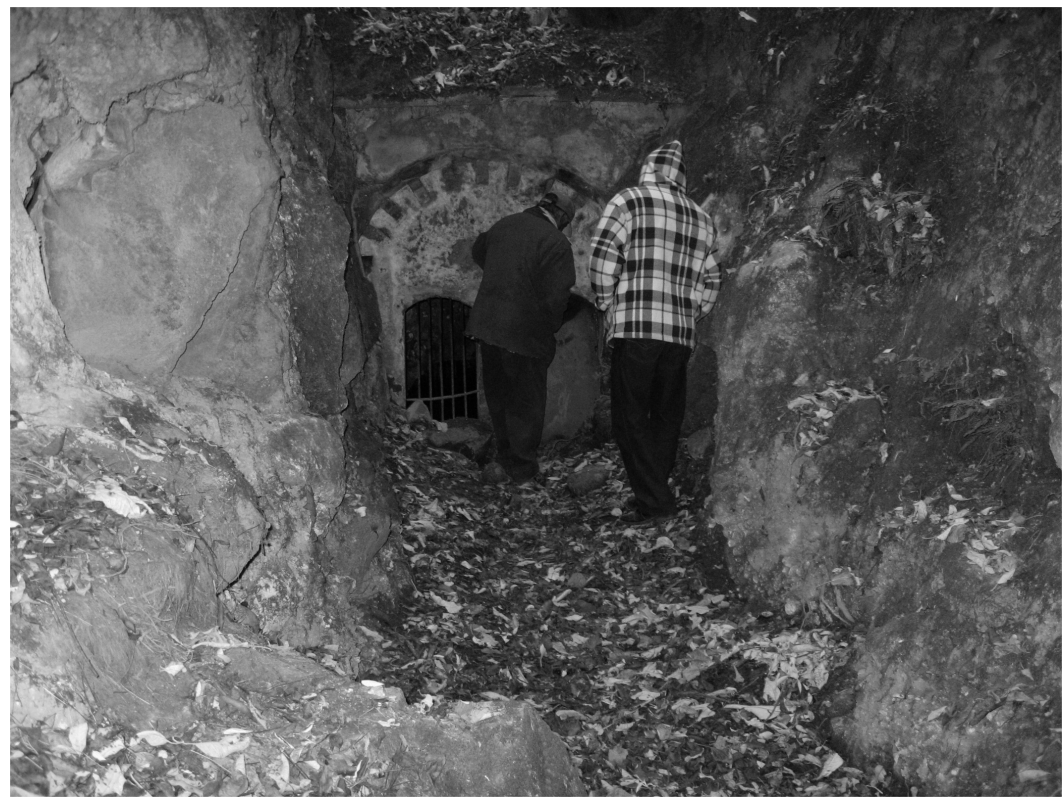

Fuente: Roberto Montes (2008).

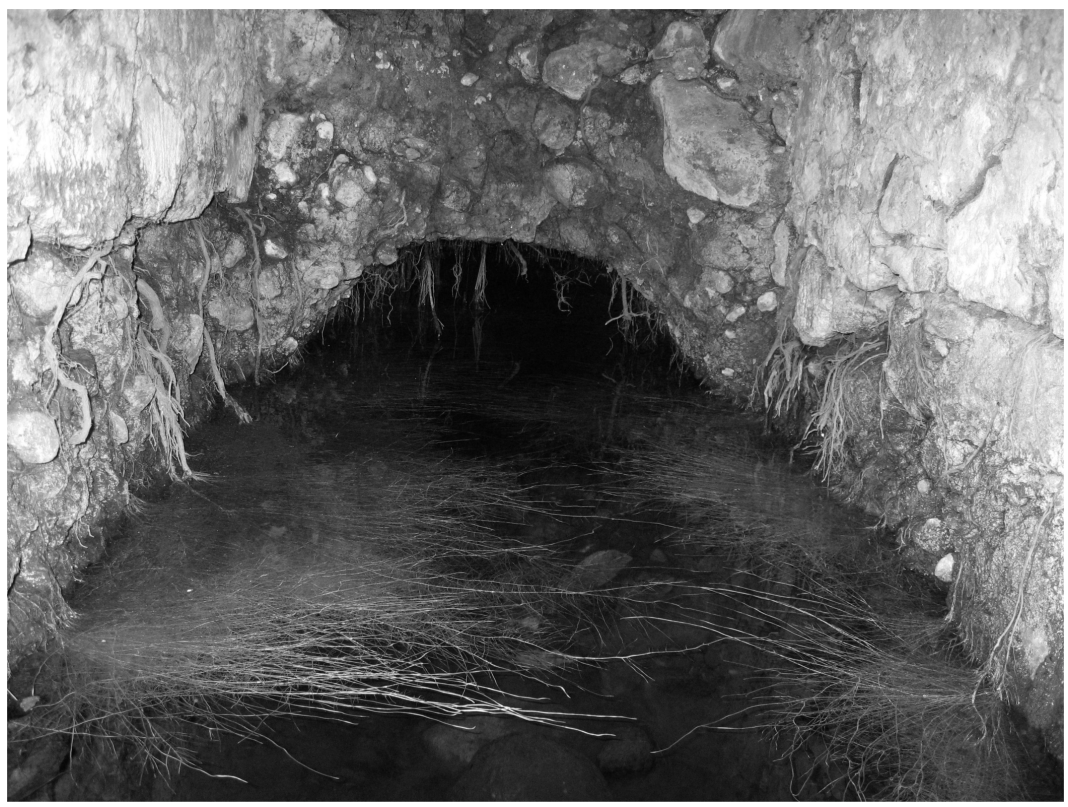

Representantes del Comité de Agua de Tepexoyuca, Ocoyoacac, muestran la galería filtrante denominada El Túnel o El Aventurero.

Fuente: Roberto Montes (2008). 
rio por toma. En esta administración estamos tratando de actualizar y controlar a los usuarios existentes.

\subsubsection{Galerias filtrantes en el curso medio del Alto Lerma}

En el mencionado Atlas ecológico de la Cuenca Hidrográfica del Río Lerma se describe el curso medio del Río Lerma que abarca siete municipios, de los cuales San Felipe del Progreso es el único en el que se georreferenció y describió el uso y manejo social del agua de dos sistemas.

\subsection{San Felipe del Progreso, galerias filtrantes denominadas El Tunal y El Salto}

Por documentación encontrada en el Archivo Histórico del Estado de México, con respecto a una contestación a la Circular no. 11, del Secretario General de Gobierno (del Estado de México), se identifica la construcción de dos galerías en el municipio de San Felipe del Progreso. "El Presidente Municipal de San Felipe del Progreso informaba sobre perforaciones ya existentes: un socavón, ubicado en el sur de la población, que mide de longitud 46 metros. La dirección media es de norte a sur, la profundidad media vertical en el extremo del socavón, mide un metro con 80 centímetros, produce agua gruesa y ésta es de temperatura templada. La producción de esta agua es espontánea, 28 de septiembre de $1932 .{ }^{8}$

\subsubsection{Ubicación de la galería filtrante}

Con la visita al lugar el día 26 de junio de 2007, se localizó el socavón reportado al sur de la cabecera municipal, a un costado del río denominado Piedras Negras, perteneciente al barrio El Tunal. Junto con el socavón descrito se encontró otro, por lo que en realidad son dos galerías filtrantes, una denominada El Tunal y otra El Salto. Ubicadas en las coordenadas X 0399109 y Y 2179631, a una altura de 2,600 metros sobre el nivel medio del mar.

\subsubsection{Uso y manejo actual del agua: infraestructura y organización social}

Respecto a la tecnología e infraestructura de los sistemas, el fontanero Enrique García Sánchez, que lleva varios años trabajando en el Departamento de Agua Potable del municipio, refiriéndose a las dos galerías, menciona que "Ese lugar [El Tunal] lo hemos ido a checar puesto que luego se tapan las boquillas. Una sola vez le hemos hecho limpieza, nos 
mandaron, tiene como dos años. Respecto a la galería filtrante de El Salto, ubicada en El Calvario, no está entubada porque su construcción y gasto no lo permite, sólo está represada. El uso del agua es público, la población del barrio viene a acarrear el agua ya sea con cubetas o con sus burros".

Se puede aseverar que el uso y manejo del agua de la galería filtrante de San Felipe del Progreso denominada El Tunal, ha estado en manos de autoridades estatales desde fechas antiguas, no así la de El Salto. En la actualidad el sistema lo maneja el ayuntamiento, por medio del $5^{\circ}$ Regidor de Agua Potable, Drenaje y Alcantarillado, atendido por el jefe del Departamento de Agua Potable, Raúl Ruiz Nava. Es posible que esta galería fuera el primer sistema de abastecimiento de agua potable de la cabecera municipal de San Felipe del Progreso.

Hasta ahora, las tomas de la galería de El Tunal están registradas junto con el padrón de la colonia Magisterial. El Sistema El Tunal abastece, de acuerdo con el padrón de usuarios correspondiente, a la Privada Justo Sierra y Peñitas (estas dos calles se abastecen también del pozo núm. 1), de la colonia Magisterial. El ayuntamiento mediante el pago que realizan los usuarios es quien da el mantenimiento correspondiente al sistema. El padrón consta de un total de 56 usuarios, de los cuales se tiene registro de sólo 10 tomas pertenecientes a la galería filtrante de El Tunal. Pero se constató en campo que hay más de 15 tomas que aún no han sido registradas ante dicho organismo, por lo cual es posible que existan más de 25 tomas abasteciéndose del sistema en cuestión.

Por comentarios de los encargados del Sistema de Agua Potable, el mantenimiento que requieren las galerías filtrantes es escaso, han transcurrido más de 11 años desde el último mantenimiento, ahora está sellada la entrada porque la población depositaba basura y realizaban desmanes. La galería filtrante de El Tunal ha sido afectada por la construcción de pozos profundos, comentan los representantes del sistema, motivando la carencia de agua que actualmente presenta.

Los administradores consideran que sería mejor tener más sistemas como éste (refiriéndose a la galería), porque no se pagaría casi nada, en comparación con los gastos en general que implican los pozos profundos, comenzando con la energía eléctrica, equipamiento, mano de obra, entre otros; y otra desventaja es que estas erogaciones deben ser constantes, de lo contrario el sistema no funciona.

\subsubsection{Galerias filtrantes en el curso bajo del Alto Lerma}

La condición geomorfológica del curso bajo, y en ella sobresale la fosa tectónica de Acambay, delimitada por la falla Pastores al Sur y al Norte, comprende la falla de Acambay. La fosa se caracteriza por una amplia zona 


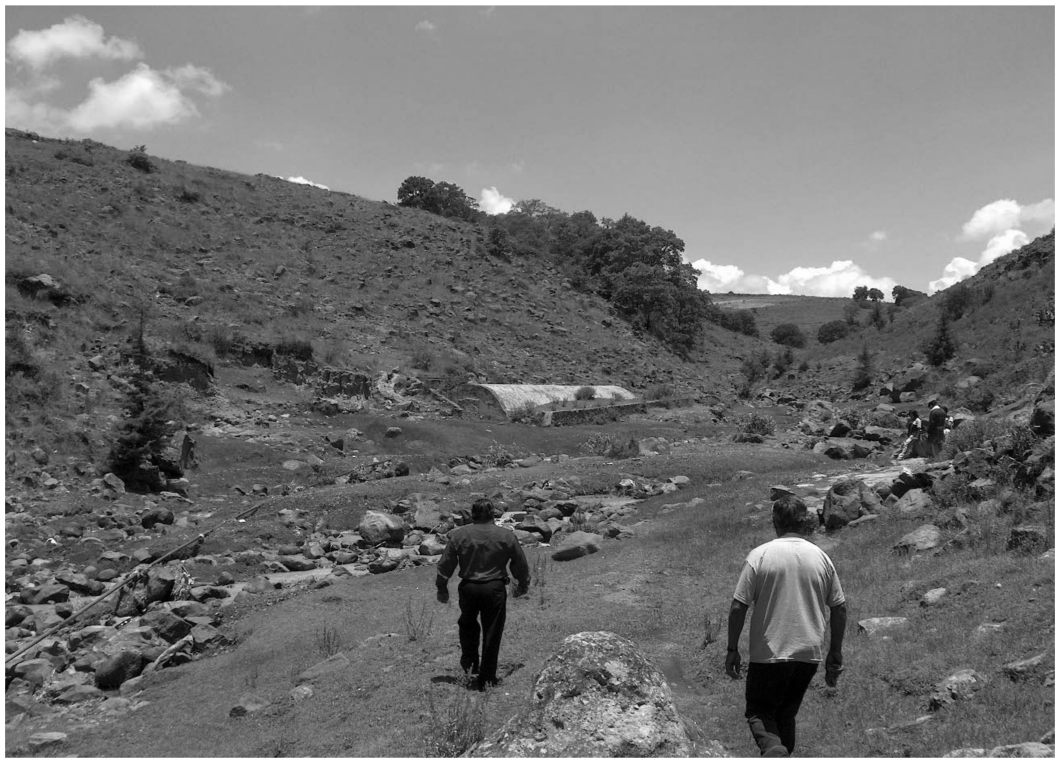

Representantes de la Regiduría de Agua Potable de San Felipe del Progreso, indican que en la parte izquierda del Cárcamo (obsoleto) se ubica la galería filtrante denominada El Tunal, con su entrada sellada.

Fuente: Roberto Montes (2007).

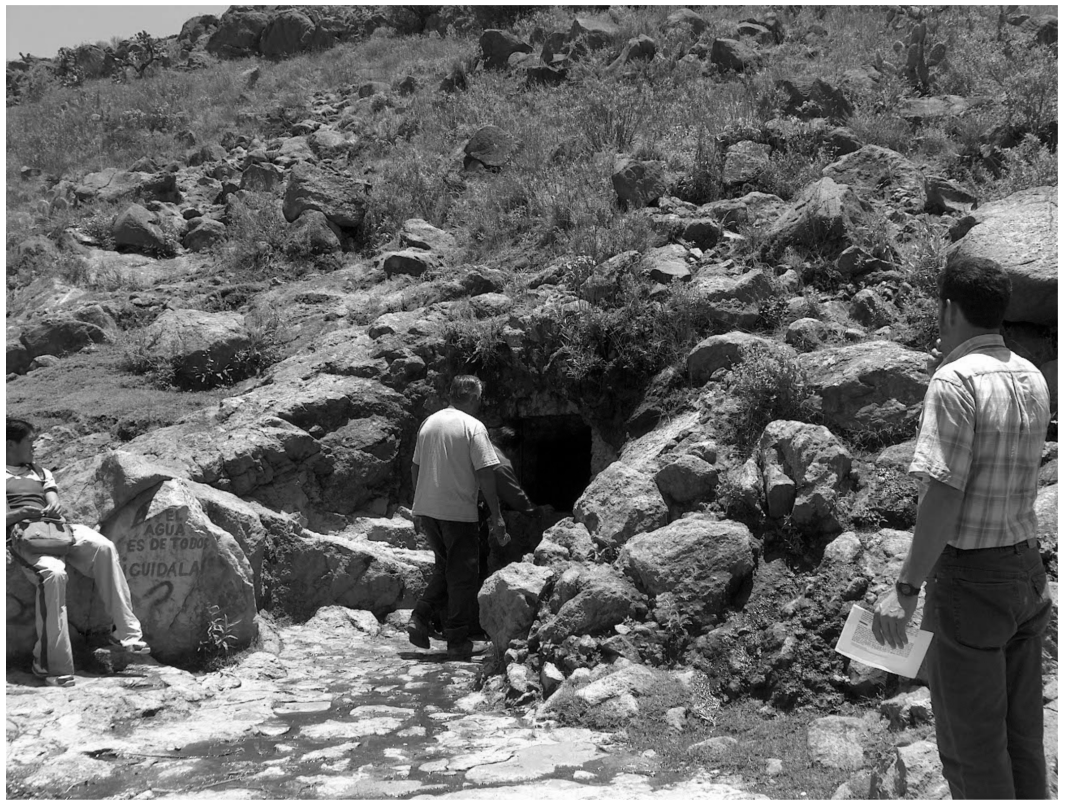

Fuente: Roberto Montes (2007). 


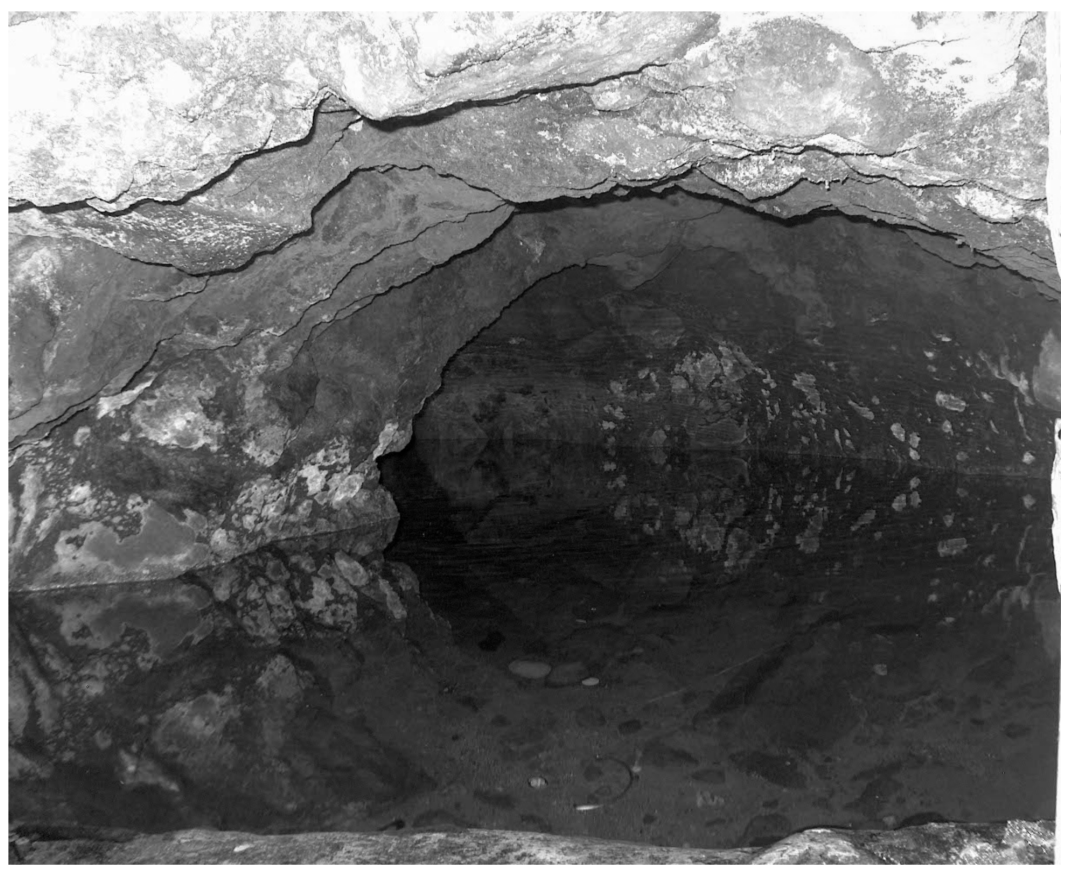

Vistas de la galería filtrante de El Salto.

Fuente: Roberto Montes (2007).

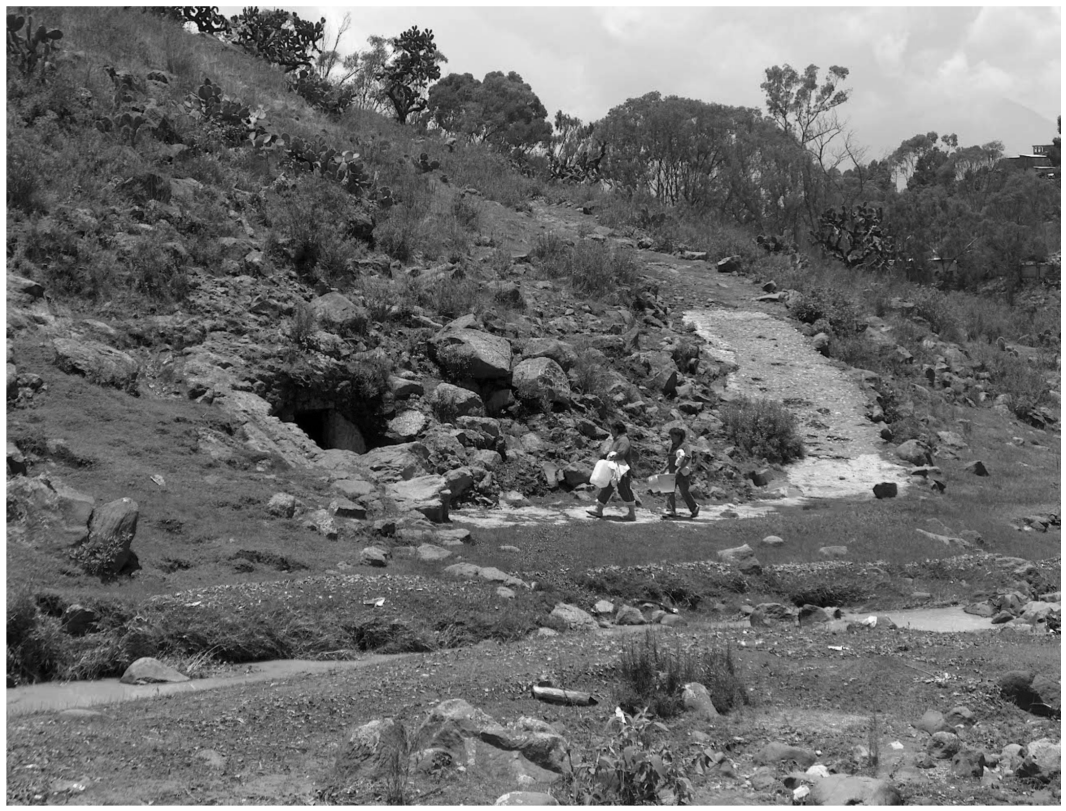

Usuarios que acuden a esta galería filtrante.

Fuente: Roberto Montes (2007). 
de sedimentación, formación de rampas acumulativas y el complejo volcánico Temascalcingo (GEM, 2000).

El curso bajo del Río Lerma (carta 2) incluye sólo tres municipios, uno de ellos, Acambay, presenta un sistema de galería filtrante y un sistema de mina de agua, ambos georreferenciados y se describe el uso y manejo social del agua.

\subsection{Acambay, galería filtrante}

Otra documentación encontrada en el Archivo Histórico del Estado de México informa la existencia de galerías filtrantes, correspondientes al municipio de Acambay. En la respuesta enviada al secretario general de gobierno del Estado, en referencia a la Circular núm. 7, girada por el Departamento de Fomento, sobre manantiales y alumbramientos de agua en el lugar, se mencionó que "Manantiales de Empathé y Mina Vieja, que más bien son galerías hechas ex profeso para el abasto de agua a esta cabecera, los que se encuentran situados uno o el primero en la cuenca de Barrancas alejadas de zona forestal y el segundo protegido por zona forestal sin explotarse; existiendo otros pequeños manantiales que sólo existen en el temporal de aguas".?

En otro escrito fechado el 20 de agosto de 1953, Hermelindo Rojas Pérez, agente federal de Hacienda, certificó el acta y bases constitutivas de la Sociedad Cooperativa de Productores "Valle de Acambay", s.C.R.L. En ella se señala lo siguiente:

En Acambay, Distrito del Oro, Estado de México, siendo las trece horas del día 20 del mes de agosto de 1953, reunidos los suscritos cuyos nombres abajo se expresan en la casa núm. 3 de la Plaza Hidalgo con el fin de construir una SOCIEDAD que por medio de Galerías Filtrantes obtenga agua potable y agua para irrigación e industria en el Valle de Acambay (galerías que se harán en el lugar denominado Puerto de Dongú empezando a una profundidad aproximada de 120 metros bajo el kilómetro 155 de la Carretera MéxicoToluca-Querétaro) "...". ${ }^{10}$

\subsubsection{Ubicación de la galería filtrante}

Durante el trabajo de campo llevado a cabo el 27 de junio de 2007, en entrevista Gerardo Plata, secretario del ayuntamiento de Acambay, mencionó que: 
$\mathrm{Al}$ respecto de la Sociedad de Galerías Filtrantes nunca se hizo nada; y en el documento dice, y está muy claro, "se harán", eso no fue llevado a cabo. Hace muchos años no había agua potable en Acambay, trajeron agua de un lugar más abajo, del Puerto, y ese puerto está a la orilla de la carretera que va a Querétaro. La toma de la Alameda se secó, hace unos diez años que fui, era por acá arriba, del barrio Endejé. Los manantiales de Empathé y Mina Vieja, en el barrio de Santiaguito, en la actualidad se encuentran y les sale agua.

Ese mismo día, Esteban Valencia García, auxiliar de la 3 a Regiduría, perteneciente a Desarrollo Urbano, Obras Públicas y Agua Potable del municipio, mostró la ubicación de Ojo de Agua y Mina Vieja.

Hay una pasando una curva, al pie de la carretera, le denominan al paraje La Herradura, rumbo a Querétaro; a mano derecha está el Ojo de Agua. La ubicación es: X: 0408961, Y: 2209092, a una altura de 2,743 metros sobre el nivel medio del mar. El manantial Ojo de Agua, allá en La Herradura, es una pequeña galería filtrante. Los que no tienen el servicio de agua de allí se abastecen, la gente carga sus garrafones en burros. Como se junta el agua y está muy limpia la acarrean. En tiempos de agua hay bastante.

Mina vieja no es una galería filtrante, sino una mina de agua ubicada al poniente a unos 300 metros colina abajo, del sistema antes descrito.

\subsubsection{Uso y manejo actual del agua: infraestructura y organización social}

Como se observa en las fotografías siguientes, la galería denominada Ojo de Agua en el paraje La Herradura, es un sistema que tiene sólo una excavación horizontal. Su uso es público y hasta la fecha no se le ha dado mantenimiento alguno.

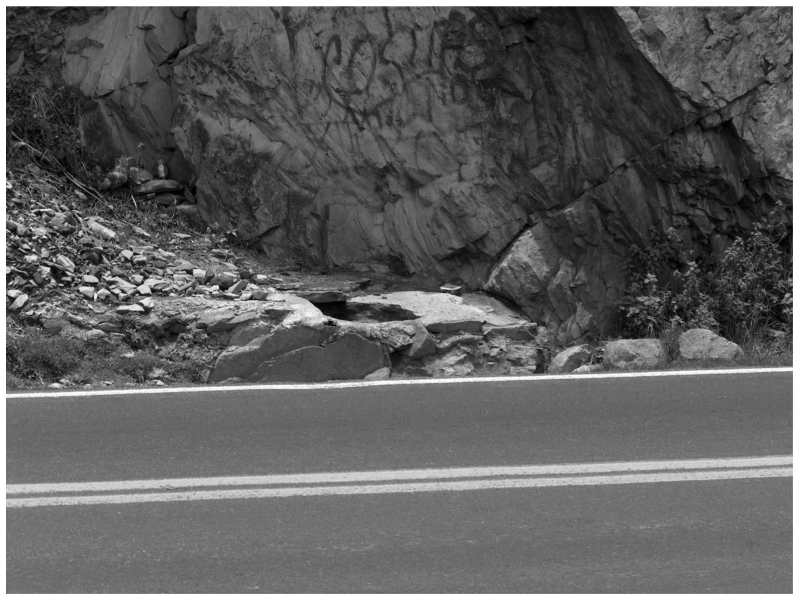

$\mathrm{Al}$ pie de la carretera se muestra el paraje La Herradura.

Fuente: Roberto Montes (2007). 


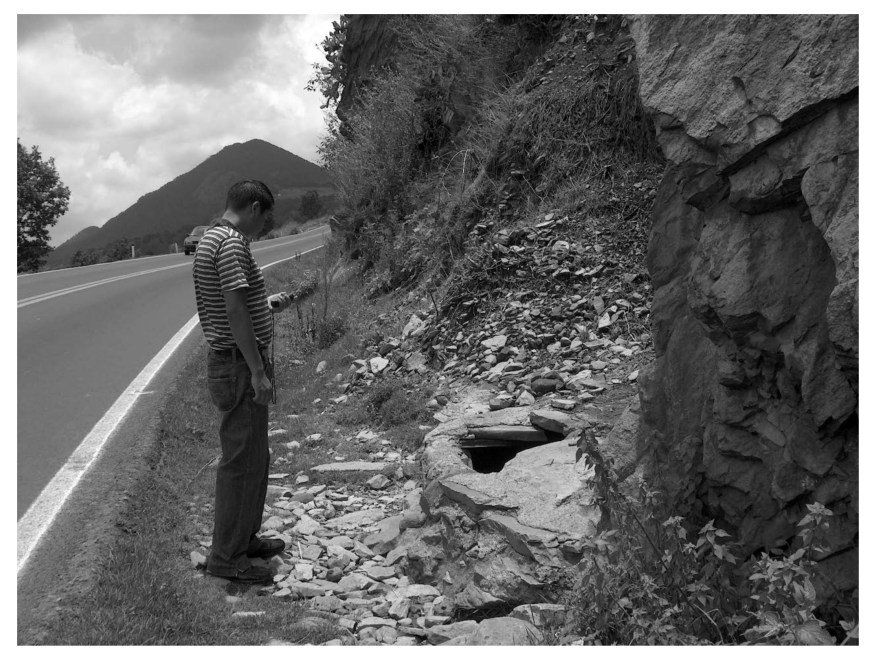

Esteban Valencia García, Auxiliar de la 3a Regiduría, frente a la perforación de Ojo de Agua (galería filtrante), Acambay.

Fuente: Roberto Montes (2007).

\section{Conclusiones}

Datación del sistema. El esbozo bibliográfico sobre el origen y difusión del qanat en el mundo apunta sin duda a regiones con ambiente del tipo desértico, específicamente en los dominios de lo que fue la antigua Persia. La infraestructura de los sistemas que se encontraron en la región del Alto Lerma es semejante a la descrita por los investigadores para zonas desérticas del Viejo Mundo, lo cual indica que la tecnología usada en ellos llegó por difusión durante o después de la colonia. Asimismo, en los casos que se contó con información, se construyeron para el servicio de las haciendas, tanto para riego como para el abasto de agua potable.

No ha sido posible encontrar documentación antigua que avale las fechas de construcción de la mayoría de los sistemas existentes en la Cuenca Alta del Río Lerma, por lo que sólo se hacen aproximaciones. Una excepción es el sistema denominado El Túnel o El Aventurero, ubicado en el Barrio de la Asunción Tepexoyuca, Ocoyoacac, donde se encuentra acuñada en una roca su posible construcción, que data del 1 de enero de 1901, es decir con más de cien años de funcionamiento. Lo único que ha cambiado es la infraestructura de conducción, y cabe la posibilidad de que originalmente el agua corriera por medio de un canal abierto de tierra. Después se encauzó por medio de tubería de barro y con el paso del tiempo, cuando se requería, se cambió por tubería de asbesto y en años más recientes por tubería de Pvc. 
Ubicación de los sistemas. La localización de los sistemas se realizó conforme al escalonamiento de los cursos de la Cuenca Alta del Río Lerma, y con base en los registros altitudinales se ubicó un sistema en el Parque Nacional Nevado de Toluca, El Túnel de Romero a 3,100 metros. El qanat ubicado en el Barrio de la Asunción Tepexoyuca está a pie de monte a una altura de 2,143 metros. Los sistemas descritos en el curso medio perteneciente a San Felipe del Progreso se localizan uno a la izquierda y otro a la derecha del río denominado Piedras Negras, en el lomerío que rodea la parte sur de San Felipe del Progreso, a una altura de 2,600 metros. Por último, la galería ubicada en el curso bajo de la cuenca se localiza en la ladera a una altura de 2,743 metros.

Manejo de los sistemas. El uso y manejo en los sistemas en la región se realiza bajo diferentes modalidades. En dos casos el funcionamiento es por medio de organizaciones autogestivas, electas de manera local, como el Comité de Agua Potable de la comunidad o barrio, cuya función es administrar, manejar y distribuir el líquido proveniente del sistema a toda la población. Otro sistema lo maneja el gobierno municipal, por medio de la regiduría encargada del agua. Dos sistemas no reciben ningún mantenimiento y no los administra organismo alguno, por lo que su acceso y uso es público.

En los sistemas manejados por organizaciones autogestivas, el ayuntamiento actúa simplemente como mediador o avalador de las elecciones realizadas para nombrar el comité encargado del sistema, acuerdos que se toman en el barrio o comunidad, según sea el caso.

Uso actual de las galerías filtrantes en el curso alto del Lerma. El uso de los sistemas, así como el gasto y explotación del agua en esta región han pasado por varias etapas. En el pasado el agua de las galerías filtrantes se utilizó para riego, en la actualidad el uso es netamente para el abasto de agua potable. Esto se debe al cambio de uso de suelo y al crecimiento urbano.

Efectos del nuevo marco jurídico sobre las formas de organización local. Las galerías filtrantes descritas fueron construidas antes de la vigencia del actual marco jurídico (Ley de Aguas Nacionales de 1992 y su reforma de 2004); asimismo, se otorgaron a las comunidades durante el reparto agrario con los procedimientos establecidos para la entrega de derechos de agua. Sin embargo, en la actualidad todos los sistemas deben ser registrados y las organizaciones de usuarios se deben formalizar según la ley. La falta de estos requisitos impide que las comunidades tengan acceso a recursos del gobierno federal para rehabilitación o ampliación de los sistemas.

Olvido, destrucción y conservación del sistema. Entre las causas que influyeron en el olvido del mantenimiento en casi todos los casos, figura el reparto agrario. En el caso del Túnel de Romero y El Aventurero, las tierras y los recursos que conformaron y daban vida a la hacienda pasaron 
a manos de la población (ejidatarios o comuneros), ignorando éstos los procesos y requerimientos fundamentales de construcción y mantenimiento del sistema. Misma situación que también llevó a la destrucción del sistema en el Barrio de Coporo, Santa María del Monte. Otra causa del abandono del sistema es la presencia de pozos profundos que afectan la recarga y saturación del manto freático debido a la sobreexplotación de agua subterránea, tal es el caso de la galería filtrante ubicada en el Centro Cultural Mexiquense, antes hacienda de La Pila, en Toluca.

Por el abandono, y al estar los túneles de las galerías filtrantes en una total oscuridad, la población de La Asunción Tepexoyuca comenzó a inventar mitos y leyendas en torno al sistema, por lo que las galerías no reciben mantenimiento alguno en la actualidad. El interés por conservar el sistema radica en la conciencia de los administradores del sistema, es el caso de los comités de agua de La Asunción Tepexoyuca, Ocoyoacac, y de San Juan de las Huertas, Zinacantepec, quienes hacen todo lo posible por conservar sus galerías filtrantes.

Sustentabilidad y modelo a seguir: las galerías filtrantes del curso alto del Río Lerma. Los distintos representantes inmersos en los sistemas descritos de la Cuenca Alta del Río Lerma están concientes de que las galerías filtrantes son sustentables, y mejor sistema abastecedor de agua (en la actualidad potable) que cualquier otra fuente que tuviesen para el abasto de sus poblaciones.

La construcción de los sistemas aquí mencionados data de más de cien años, lo que claramente indica que no se requirieron estudios y técnicas modernas para su construcción. No obstante, se aprecian los conocimientos empíricos aplicados en la construcción y manejo del sistema por parte de sus constructores. Por otro lado, el que estos sistemas en la región tengan más de cien ańos y que estén en funcionamiento muestra sus bondades y permanencia en el tiempo. Es importante insistir y resaltar el bajo costo que implica el mantenimiento de la galería filtrante, ya que es necesario efectuarlo sólo en caso de colapso del túnel o simplemente para limpiar el azolve de las cajas o represas desarenadoras. Todo ello se realiza según el conocimiento local que se tiene de la consolidación del material donde fue construido el sistema. El mantenimiento se efectúa entre uno y cada 15 años. Sólo las líneas principales de conducción del agua requieren mayor vigilancia, y su revisión se realiza más de tres veces al año (acentuada en época de lluvias).

Respecto a los pozos profundos, las galerías filtrantes son una mejor alternativa porque no requieren electricidad para su operación, ni implican mantenimiento de bombas de los pozos y de los estudios constantes que éstos deben tener para cumplir con las normas y requerimientos dispuestos en las instancias federales con respecto al agua. 
Las galerías filtrantes no dependen de algún tipo de energía externa para la extracción de agua, todo el sistema fluye y se distribuye de manera natural y sustentable, por gravedad. El sistema de galerías filtrantes es sustentable y presenta un diseño aplicable a distintos lugares con fines de abastecimiento de agua potable, ya que su durabilidad tecnológica y de infraestructura hacen posible un abasto continuo del líquido.

Con este sistema es posible combatir y dar una solución a la escasez de agua en la Cuenca Alta del Río Lerma, donde las características fisiográficas e hidrológicas lo permitan.

\section{Bibliografía}

Blanquel-Morán, Mario y Lorena Hernández Reyes (1999), Monografía municipal de San Felipe del Progreso, Gobierno del Estado de México-Asociación Mexiquense de Cronistas Municipales A. C.Instituto Mexiquense de Cultura, México.

Blázquez, Luis (1957), "Hidrogeología de una parte del Valle de Tehuacán, Estado de Puebla", Anales del Instituto de Geología, t. XII, Universidad Nacional Autónoma de México, México, pp. 9-55.

Castañeda-González, Rocío (1998), "Esfuerzos públicos y privados para el abasto de agua a Toluca (1862-1910)", en Blanca Estela Suárez Cortez (coord.), Historia de los usos de agua en México: oligarquias, empresas y ayuntamientos, 1840-1940, Comisión Nacional del Agua-CIESAS-IMTA, México, pp. 107-177.

Cleek, Richard K. (1973), “The Infiltration Gallery in México: Two Diffusion”, Antropos, 68, pp. 897-909.

Fabila, Alfonso y Gilberto (1951), México, ensayo socioeconómico del Estado, vol. I. Talleres Gráficos de la Nación, México.

Furon, Raymond (1967), “Los acueductos subterráneos”, El agua en el mundo, Alianza, Madrid, pp. 90-97.

GEM (Gobierno del Estado de México) (1993), Atlas ecológico de la Cuenca Alta del Río Lerma, t. I, Cartografía, GEM, México.

Henao, Luis Emilio (1980), Campesinado e irrigación, Edicol, México. 
INEGI (Instituto Nacional de Estadística, Geografía e Informática) (2003), Carta Topográfica E14-A37 (San Miguel Zinacantepec), INEGI, México.

Laureano, Prieto (2001), Atlas del agua. Los conocimientos tradicionales para combatir la desertificación, UNESCO-LAIA, Barcelona.

Martínez-Saldaña, Tomás, Cristina Martínez y Herberth E. McKintoch (2005), "Las galerías filtrantes, una historia de éxito en Santa María de las Parras", Boletín del Archivo Histórico del Agua, año 10, 31, México, pp. 7-16.

Molina, Eduardo (1949), "El proyecto lerma”, Las Obras de Lerma. Trabajos presentados al Primer Congreso Internacional de Ingeniería Civil, celebrado en la Ciudad de México, Departamento del Distrito Federal, México.

Monterrosa-Prado, Mariano (1976), "Las galerías filtrantes", Cuadernos de Culhuacán, año II, I (2), seP-INAH, México, pp. 57-61.

Montes-Hernández, Roberto (2005-2008), Notas de trabajo de campo.

Norton-Lenard, Jonathan y el equipo editorial de libros Time-Life (1982), "El próximo oriente, cuna de la agricultura", La revolución del Neolítico, Time-Life Internacional de México, México.

Palerm-Viqueira, Jacinta, et al. (2001), "Técnicas hidráulicas en México, paralelismos con el Viejo Mundo. II. Galerías filtrantes (qanats)", II Encuentro sobre Historia y Medio Ambiente, 24 al 26 de octubre, Huesca, España, <http://www.geocities.com/bimbaletes/, http:// www.geocities.com/jacinta_palerm/ buenos_aires.pdf>, 29 de octubre de 2004.

Palerm-Viqueira, Jacinta (2002), "Cuadro localización galerías filtrantes (qanats) en México", <http://www.geocities.com/jacinta_palerm/ galerias/cuadrogalerias.html>, diciembre de 2004 .

Peña-Manjarrez, Vicente (2000), Atlas Ecológico de la Cuenca Hidrográfca del río Lerma: Industria, Gobierno del Estado de México-UAEM, Toluca, México.

Romero-Contreras, A. Tonatiuh (1998), Comentario personal. 
Romero-Contreras, A. Tonatiuh (2005), Comentario personal.

Seele, Enno (1969), "Galerías filtrantes en el área de Acatzingo-Tepeaca, Estado de Puebla”, Boletín del Instituto Nacional de Antropología e Historia, 35, México, pp. 3-8.

Sugiura, Yoko, Patricia Martel y Sandra Figueroa (1997), Atlas etnográfico de la Cuenca Alta del Río Lerma. Otomies, mazahuas, matlazincas y nahuas en los 32 municipios, Comisión Coordinadora para la Recuperación Ecológica de la Cuenca Alta del Río LermaGobierno del Estado de México, Toluca, México.

Wilken, Gene C. (1990). “Las galerías filtrantes de México”, en Modesto Suárez (coord.), Historia, antropología y politica. Homenaje a Ángel Palerm, Alianza Editorial Mexicana, México, pp. 275-305.

\section{Archivos consultados}

Archivo Histórico del Estado de México, Comisión Agraria Mixta (АHEM/ C.A.M.).

Archivo Histórico del Estado de México, Fondo: Fomento; Serie: Aguas (AHEM/F.A.).

Archivo Histórico del Estado de México, Dirección General de Comunicaciones y Obras Públicas (DC. AP).

Recibido: 13 de enero de 2009. Reenviado: 8 de julio de 2010. Aceptado: 4 de agosto de 2010.

Roberto Montes-Hernández. Es licenciado en geografía y ordenación del territorio por la Universidad Nacional Autónoma de México; maestro en ciencias agropecuarias y recursos naturales por la misma universidad. Actualmente cursa el doctorado en ciencias agropecuarias y recursos naturales en la Universidad Autónoma del Estado de México. Colaboró en la realización de la parte histórica del Atlas Industrial de la Cuenca Alta del Río Lerma, Toluca, México, marzo de 2000; así como en la edición de la Revista Pangea de la Facultad de Geografía, UAEm, durante el periodo comprendido de julio de 1999 a enero de 2001. Sus líneas de investigación son: historia en el Atlas Industrial de la Cuenca Alta del Rí Lerma y el uso 
y manejo social del agua. Entres sus publicaciones destacan: en coautoría, "Historia del manejo social del agua en la subcuenca del río Tejalpa, Estado de México", en Daniel Murillo y Jacinta Palerm (eds.), Memorias I Congreso Red Investigadores Sociales sobre Agua, Instituto Mexicano de Tecnología del Agua, Jiutepec, México (2010), <http://redissa.hostei.com/ rissa/Mesas_2010.htm>.

Alejandro Tonatiuh Romero-Contreras. Es doctor en antropología social por la Universidad Iberoamericana. Actualmente es profesor-investigador de tiempo completo en el Centro Interamericano de Recursos del Agua (CIRA) de la UAEM. Su línea de investigación actual es gestión integrada del agua. Entre sus publicaciones destacan: "El pequeño regadío en la obra de Kart Wittfogel: una discusión inacabada”, en A media legua, repensando el desarrollo rural, Universidad Autónoma del Estado de México, Toluca (2007); “Uso del agua en los temascales de San Andrés Cuexcontitlán”, en Memorias del Congreso Internacional sobre Turismo Rural y Desarrollo Sustentable, Brasil, mayo de 2007; "Caracterización social del pequeño regadío: teorías y experiencias", en Acercamientos conceptuales y metodológicos para el estudio de la realidad agropecuaria y rural de México, Universidad Autónoma del Estado de México, Toluca (2009).

Carlos Solís-Morelos. Es licenciado en ingeniería civil por la Universidad Autónoma de Puebla; maestro en ingeniería sanitaria y ambiental por la Universidad de Cantabria, Espańa y doctor en ingeniería por la Universidad Autónoma del Estado de México. Actualmente es profesor-investigador del Centro Interamericano de Recursos del Agua, de la Facultad de Ingeniería, UAEM. También actualmente dirige la Coordinación del Centro Interamericano de Recursos del Agua y de la Red Lerma-ChapalaSantiago. Sus líneas de investigación son: riego y drenaje. Es autor de diversos artículos con énfasis en la potabilización de agua y fuentes de abastecimiento y sistemas de tratamiento de aguas residuales. Entre sus publicaciones destacan: "Técnico sobre los avances en el diseño de lagunas de estabilización", Tecnología del Agua, Barcelona; "Avances en el diseño de lagunas de estabilización", texto para la materia de ingeniería sanitaria (UAEM); "Procesos y operaciones unitarias en la ingeniería sanitaria”, texto para la materia de ingeniería sanitaria (UAEM).

María Gladys Rivera-Herrejón. Es licenciada en economía por la Universidad Autónoma del Estado de México; maestra en economía por el Centro de Investigación y Docencia Económicas (CIDE); doctora en ciencias sociales con especialidad en desarrollo rural por la Universidad Autónoma Metropolitana. Ha escrito tres libros y es editora de cuatro 
más. Además, es autora y coautora de más de 50 artículos y capítulos de libro sobre la agricultura mexicana y la sociedad rural. Es investigadora nacional, nivel ir por el Consejo Nacional de Ciencia y Tecnología de México. Actualmente se desempeña como investigadora y docente en el Instituto de Ciencias Agropecuarias y Rurales (ICAR) de la Universidad Autónoma del Estado de México.

Sergio Zamorano-Camiro. Es licenciado en sociología por la Universidad Nacional Autónoma de México y maestro en sociología por la Universidad Autónoma del Estado de México. Ha sido profesor en la Facultad de Ciencias Políticas y Administración Pública de la UaEm por más de 20 años y se ha desempeñando como coordinador de la carrera de Sociología y como subdirector académico de la misma facultad. Actualmente se desempeña como director del Área de Organización y Capacitación de Productores Rurales, en la Dirección de Desarrollo Rural de la Secretaría de Desarrollo Agropecuario del Gobierno del Estado de México. Es autor de diversos artículos sobre sociología rural. Entre sus publicaciones sobresalen: "Proyectos productivos para el desarrollo de localidades rurales", Páramo del Campo y la Ciudad, 11, семapem, Toluca; "Desruralización", A media legua. Repensando el desarrollo rural, UAEM; en coautoría: "Indicadores sociales de sustentabilidad en dos comunidades campesinas del Valle de Toluca, México", A media legua. Repensando el desarrollo rural, UAEM. 